\title{
Oxygen Vacancies in Tungsten Oxide and Their Influence on Tungsten Oxide/Silicon Heterojunction Solar Cells
}

\author{
Mathias Mews ${ }^{\mathrm{a}, *}$, Lars Korte ${ }^{\mathrm{a}}$, Bernd Rech ${ }^{\mathrm{a}}$ \\ ${ }^{a}$ Helmholtz-Zentrum Berlin, Institute of Silicon Photovoltaics, Kekuléstraße 5, D-12489 Berlin, Germany
}

\begin{abstract}
Tungsten oxide $\left(\mathrm{WO}_{x}\right)$ can be incorporated into amorphous/crystalline silicon heterojunction solar cells as hole contact and for interface modification between p-type amorphous silicon and indium tin oxide. This paper aims at understanding the influence of tungsten oxides properties on silicon heterojunction solar cells. Using in-system photoelectron spectroscopy on thermally evaporated $\mathrm{WO}_{x}$ layers, it was verified that $\mathrm{WO}_{x}$ with a stoichiometry close to $\mathrm{WO}_{3}$ features a work function close to $6 \mathrm{eV}$ and is therefore suitable as hole contact on silicon. Additionally the oxygen vacancy concentration in $\mathrm{WO}_{x}$ was measured using photoelectron spectroscopy. High oxygen vacancy concentrations in $\mathrm{WO}_{x}$ lead to a low band bending in the $\mathrm{WO}_{x} /$ silicon-junction. Furthermore solar cells were fabricated using the same $\mathrm{WO}_{x}$, and the band bending in these cells is correlated with their fill factors (FF) and open circuit voltages ( $\left.\mathrm{V}_{\mathrm{OC}}\right)$. Combining these results, the following picture arises: Positively charged oxygen vacancies raise the Fermi-level in $\mathrm{WO}_{x}$ and reduce the band bending at the $\mathrm{WO}_{x} /$ silicon-junction. This, in turn, leads to reduced $\mathrm{V}_{\mathrm{OC}}$ and FF. Thus, when incorporating $\mathrm{WO}_{x}$ into silicon solar cells it is important to minimize the oxygen vacancy density in $\mathrm{WO}_{x}$. Therefore deposition methods, enabling adjustment of the $\mathrm{WO}_{x}$ stoichiometry are preferable.
\end{abstract}

Keywords: amorphous/crystalline silicon heterojunction solar cells, tungsten oxide hole collector, x-ray photoelectron spectroscopy, high work function metal oxide hole contacts

\section{Introduction}

Amorphous/crystalline silicon heterojunction solar cells have enabled the highest efficiency of all silicon wafer based solar cells [1]. The main advantage of silicon heterojunction solar cells is their excellent contact passivation by intrinsic amorphous silicon ((i)a-Si:H), which enabled open circuit voltages $\left(\mathrm{V}_{\mathrm{OC}}\right)$ of up to $750 \mathrm{meV}$ [2].

Recently researchers focused on the carrier transport across the indium-tin-oxide (ITO)/p-type amorphous silicon ((p)a-Si:H) junction [3, 4]. During this studies it was found that the low work function of indium-tin-oxide [4] and aluminum doped zinc oxide [5,6] limits the carrier transport across the interface between the transparent conductive oxide and the p-type amorphous silicon [5, 4].

\footnotetext{
* corresponding author

Email address: mathias.mews@helmholtz-berlin.de (Mathias Mews)
} 
This has incited a number of works on different high work function metal oxides like molybdenum oxide [7], tungsten oxide [8] and vanadium oxide [9] as hole contacts on silicon solar cells, or for band alignment adjustment at the $\mathrm{TCO} /(\mathrm{p}) \mathrm{a}-\mathrm{Si}: \mathrm{H}$-junction [4]. Recently interest has shifted towards the direct application of high work function metal oxides as hole contacts on (i)a-Si:H passivation layers $[10,8]$, which already yielded $22.5 \%$ efficiency for molybdenum oxide hole contacts [11], with a conventional (n)a-Si:H electron contact. One advantage of this approach is the lower parasitic absorption in metal oxides as compared to doped amorphous silicon contacts [10].

Also low work function materials were applied as electron contacts leading to $20.5 \%$ efficiency for $\mathrm{TiO}_{x}$ [12] with a diffused hole contact, $14 \%$ efficiency for $\mathrm{Cs}_{2} \mathrm{CO}_{3}$ with a PEDOT:pss hole contact [13] and $19.4 \%$ efficiency with a lithium floride electron contact and a molybdenum oxide hole contact deposited on (i)a-Si:H passivation layers [14]. Molybdenum oxide has been widely applied as a hole collection layer in organic solar cells [15, 16] and later transferred to silicon based devices to fulfill the same function. Multiple studies found that molybdenum oxide contacts on silicon degrade under annealing at $200^{\circ} \mathrm{C}[8,11]$ and atomic layer deposition of molybdenum oxide at higher temperature was also found to yield low quality contacts $[17,18]$. Therefore silicon heterojunction solar cells with molybdenum oxide contacts degrade significantly during curing of common silver pastes [11].

In contrast tungsten oxide, which was also applied as hole collection layer in organic solar cells [15, 16], is stable during annealing at $200^{\circ} \mathrm{C}$ [8] and yields better fill factors than molybdenum oxide, when applied for interface modification at the $\mathrm{TCO} /(\mathrm{p}) \mathrm{a}-\mathrm{Si}: \mathrm{H}$ interface [8]. Unfortunately tungsten oxide hole contact layers deposited directly on (i)a-Si:H passivation layers [8], or n-type crystalline silicon [9] only yield comparatively low fill factors and limited open circuit voltages.

The present article studies $\mathrm{WO}_{x}$ as an interlayer, or hole contact in SHJ solar cells and investigates the influence of its chemical structure on solar cell properties. The reason for the low performance of thermally evaporated tungsten oxide hole contacts on silicon is identified and a way to improve the material is proposed.

\section{Materials and methods}

\subsection{Preparation of tungsten oxide}

Tungsten oxide was deposited by thermal evaporation at $920^{\circ} \mathrm{C}$ from a tungsten crucible onto a substrate kept at ambient temperature. The depositions were conducted in an ultrahigh vacuum system with a base pressure of $1 \times 10^{-9}$ mbar. The substrates were either crystalline silicon wafers, or nominally identical wafers covered by $6 \mathrm{~nm}$ intrinsic amorphous silicon. These substrates were dipped in diluted hydrofloric acid (1\%, $1 \mathrm{~min})$ before they were transfered into the ultra high vacuum system. The source material was tungsten oxide $\left(\mathrm{WO}_{3}\right)$ powder with a purity of $99.99 \%$ from Alfa Aesar. The deposition rate was varied from 0.3 to $2 \mathrm{~nm} / \mathrm{min}$ to attain different stoichiometry and oxygen vacancy concentrations in these layers.

Selected layers were exposed to oxygen plasma treatments in the same chamber at an oxygen pressure of $1 \times 10^{-5} \mathrm{mbar}$ 
for $10 \mathrm{~min}$. These layers were neither included in solar cells, nor used for work function measurements. Instead they were only used to attain $\mathrm{x}$-ray photoelectron spectra of near stoichiometric layers.

\subsection{Solar cell process}

Single $1 \times 1 \mathrm{~cm}$ solar cells were prepared on $3 \times 3 \mathrm{~cm}$ pieces of $280 \mu \mathrm{m}$ thick, polished phosphorous doped floatzone grown c-Si wafers with (111) surface orientation and a resistivity of $3 \Omega \mathrm{cm}$. Wafers were cleaned using the RCA process and dipped in diluted hydrofloric acid (1\%, $2 \mathrm{~min})$ before layer deposition. Then intrinsic a-Si:H passivation layers were deposited using plasma enhanced chemical vapor deposition with $13.56 \mathrm{MHz}$ excitation, a process pressure of $0.5 \mathrm{mbar}$, a substrate temperature of $170^{\circ} \mathrm{C}$, an electrode distance of $3 \mathrm{~cm}$, a plasma power density of $19 \mathrm{~mW} / \mathrm{cm}^{2}$, and a silane flow of $10 \mathrm{sccm}$. Afterwards the layers were exposed to a hydrogen plasma treatment step to decrease the interface defect density at the silicon heterojunction [19]. The plasma parameters were 1 mbar process pressure, a power density of $56 \mathrm{~mW} / \mathrm{cm}^{2}$, a substate temperature of $170^{\circ} \mathrm{C}$, an electrode distance of $5 \mathrm{~cm}$ and a hydrogen flow rate of $20 \mathrm{sccm}$. For solar cell fabrication wafers were coated with $4 \mathrm{~nm}$ intrinsic a-Si:H and $8 \mathrm{~nm}$ n-type a-Si:H on the backside and $5 \mathrm{~nm}$ intrinsic a-Si:H and tungsten oxide layers with thicknesses of 5 to $30 \mathrm{~nm}$ on the front side. These $\mathrm{WO}_{x}$ layers were also prepared in the ultra high vacuum system. Reference solar cells were coated with $8 \mathrm{~nm}$ p-type a-Si:H instead of tungsten oxide on the front side. The solar cells were then completed by ITO sputtering at room temperature and from a ceramic target. Afterwards the samples were annealed for $5 \mathrm{~min}$ at $200^{\circ} \mathrm{C}$ and metalized with Ti/Ag stacks. The full solar cell process is discussed elsewhere.[20]

\subsection{Photoelectron spectroscopy}

All photoelectron spectroscopy measurements were conducted in the same UHV system as the tungsten oxide evaporation. The chamber for photoelectron spectroscopy measurements is connected to the evaporation chamber, but the connection is interrupted during depositions and measurements. The base pressure in the whole measurement and deposition set-up is $1 \times 10^{-9}$ mbar. He-UPS measurements with an excitation energy of $21.2 \mathrm{eV}$ were conducted directly after the depositions (maximum 20 minutes between deposition and measurement), since He-UPS is very surface sensitive and contaminations such as adsorbates from the residual gas could influence the work function of the samples. The work function was determined by fitting a Boltzmann sigmoid function to the secondary electron cut-off.

X-ray photoelectron spectroscopy was applied to obtain the stoichiometry of tungsten oxide layers. The tungsten $4 \mathrm{f}$ core level was measured and fitted according to the analysis presented by Bussalotti et al. [21] and adjusted by other groups $[22,23]$. According to this interpretation the $4 \mathrm{f}$ orbital signal of tungsten oxide consists of a doublet of the $7 / 2$ and $5 / 2$ spin states with an energy shift of $2.12 \mathrm{eV}$ between the two components of the doublet, an intensity ratio of 0.75 and the same full with at half maximum for both peaks.

Each doublet consists of three signals. One is the signal of $\mathrm{W}^{6+}$, which has a binding energy of about $35.9 \mathrm{eV}$ for 
the $7 / 2$ spin state. This is stoichiometric tungsten trioxide $\left(\mathrm{WO}_{3}\right)$. The second signal is $\mathrm{W}^{5+}\left(\mathrm{W}_{2} \mathrm{O}_{5}\right)$ and its binding energy was kept as a fixed energy distance of $1.2 \mathrm{eV}$ lower than the one of $\mathrm{W}^{6+}$. Finally the third signal is located $0.5 \mathrm{eV}$ above the binding energy of $\mathrm{W}^{6+}$ and is related to the barrier height inhomogeneity (BHI) [24] induced by oxygen vacancy defects at the tungsten oxide surface. Note that the signal of the BHI is purely surface related and absent from samples measured with atmospheric contaminations like adventitious carbon [25]. Therefore in-system measurements without a vacuum break are instrumental for an analysis of this property.

Fitting of the data with only one, or two signals per doublet was done, but three signals and especially a signal with a binding energy of about 0.5 to $0.6 \mathrm{eV}$ above the binding energy of $\mathrm{W}^{+}$are needed to attain good fits to the data.

All in all this fit model has seven fitting parameters, being the binding energy of the $\mathrm{W}^{6+} 7 / 2$ spin state, which also determines all other binding energies, and the three intensities and three full withs at half maximum of the three signals.

\subsection{Other measurements and numerical device simulation}

Surface photo voltage measurements with $905 \mathrm{~nm}$ laser excitation [26] were used to measure the band bending in samples with tungsten oxide on n-type crystalline silicon, or n-type crystalline silicon with intrinsic amorphous silicon passivation layers and in finished solar cells. The passivated back side of the finished solar cells increases the decay time of the voltage pulse, since recombination at this interface is suppressed. This is of no consequence to the measured value of the voltage pulse. Additionally the n-doped layer on the back-side fixes the Fermi-level at the back-side and provides a defined back contact. Therefore surface photo voltage measurements on finished solar cells should be less variable than on samples with unprocessed back-sides.

Solar cell measurements were conducted using a solar simulator with class AAA AM1.5GMM illumination at $25^{\circ} \mathrm{C}$. The numerical device simulator AFORS-HET [27] was used to simulate the carrier extraction from a crystalline silicon absorber using different contact systems. The simulation model consisted of $250 \mu \mathrm{m}$ thick n-type crystalline silicon symmetrically passivated by $5 \mathrm{~nm}$ intrinsic hydrogenated amorphous silicon. The a-Si:H layers were simulated using an electron affinity of $3.724 \mathrm{eV}$, a band gap of $1.68 \mathrm{eV}$. The charge selective contacts were implemented by defining two Schottky-contacts with a recombination velocity of $1 \mathrm{~cm} / \mathrm{s}$ for one carrier type effectively blocking the extraction of this carrier type and $1 \times 10^{7} \mathrm{~cm} / \mathrm{s}$ for the other. Tunneling through the Schottky barrier was used as carrier transport mechanism.

\section{Results and discussion}

\subsection{Device simulation}

The band alignment at the hole and electron contacts of a solar cell depends largely on the work functions of the respective contact materials. Numerical device simulations were employed to investigate the influence of the contact 


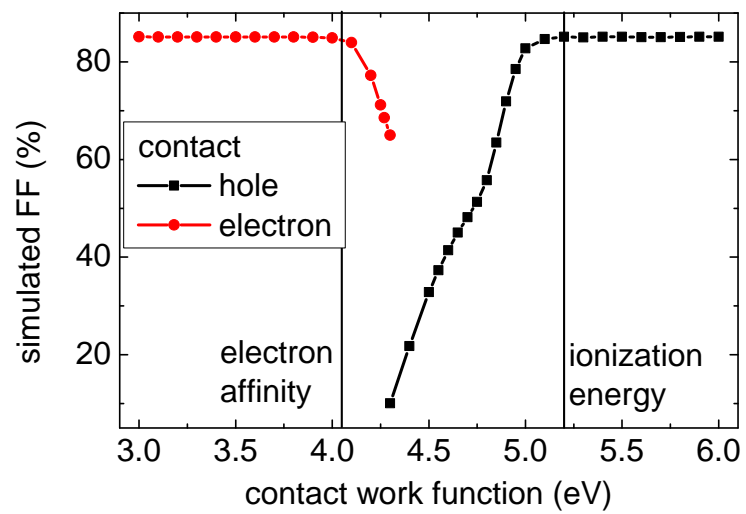

Figure 1: Simulation of the fill factor of a solar cell consisting of an n-type crystalline silicon absorber, symmetrically passivated by intrinsic hydrogenated amorphous silicon, with a carrier selective contact on either side. The work function of the electron contact layer was set to $3 \mathrm{eV}$, while the hole contact work function was varied. Similarly the hole contact work function was set to $6 \mathrm{eV}$, while the electron contact work function was varied. The vertical lines mark the electron affinity and ionization energy of crystalline silicon.

work function on the solar cell properties and to identify the appropriate work functions for both contacts. For this simulation the device structure was defined as an n-type crystalline silicon wafer, symmetrically passivated by intrinsic hydrogenated amorphous silicon layers with charge selective contacts on both sides of the wafer. Figure 1 displays the simulated solar cell fill factor values for varying contact work function. The hole contact work function was set to $6 \mathrm{eV}$, while the work function of the electron contact was varied from $3 \mathrm{eV}$ to $4.3 \mathrm{eV}$. The solar cell fill factor remains constantly at about $85 \%$ as long as the work function of the electron contact is below $4.05 \mathrm{eV}$, which is the electron affinity of crystalline silicon i.e. the distance of its conduction band to the vacuum level. The fill factor decreases for work functions above $4.05 \mathrm{eV}$, since the contact work function is then higher than the electron affinity and a transport barrier is introduced at the electron contact. The numerical simulation becomes unstable if the electron contact's work function is higher than $4.3 \mathrm{eV}$, since electrons generated in the crystalline silicon absorber are no longer efficiently extracted.

Similarly the hole contact's work function was varied, while the electron contact's work function remained at $3 \mathrm{eV}$. The fill factor is stable at about $84 \%$ for hole contact work functions from 5.4 to $6 \mathrm{eV}$. Once the hole contact's work function is below $5.4 \mathrm{eV}$, the fill factor decreases with decreasing work function. The reason is the introduction of a hole transport barrier at the interface, since the contact work function is lower than the ionization energy of crystalline silicon and therefore above the valence band of crystalline silicon.

A similar simulation for the work function of the transparent conductive oxide layers on the hole and electron contacts [4] found a less severe impact of the work functions. This is mainly because the high carrier concentrations in the p- and n-doped contact layers and the transparent conductive oxides mitigate the impact of the non optimal band alignment. In the present simulation even a slight transport barrier has a great detrimental impact on the fill factor, because no highly doped layers are included in the model and the band bending in the device fully depends on the 


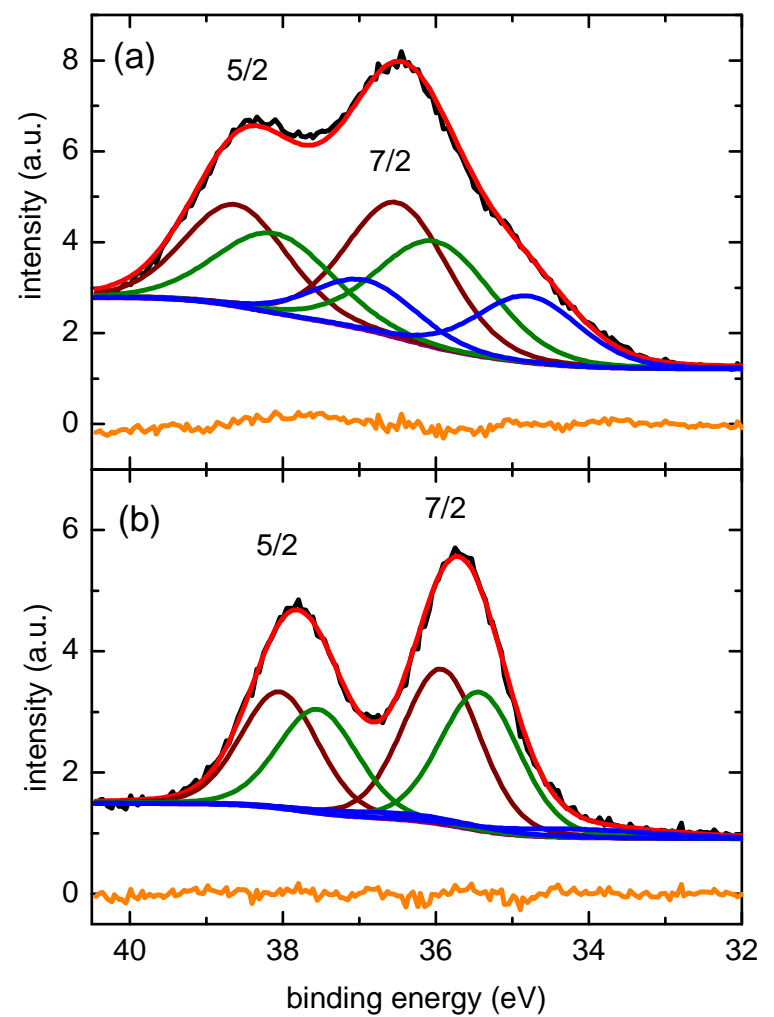

Figure 2: XPS spectra of $\mathrm{WO}_{2.89}$ (a) and $\mathrm{WO}_{2.97}$ (b). The measured data (black) was fitted with the sum (red) of the doublets of W6+ (green), W5+ (blue), the signal shifted by oxygen vacancies (brown) and a Shirley background (violet). The residual (orange) is also shown.

work function differences between the absorber and the contact layers.

Overall it can be concluded that efficient carrier selective contacts on silicon must have an appropriate work function. A work function higher than $5.5 \mathrm{eV}$ is needed for the hole contact and a work function below $4 \mathrm{eV}$ is needed for the electron contact.

\subsection{Chemical analysis of tungsten oxide}

Tungsten oxide was deposited by thermal evaporation and then analysed by photoelectron spectroscopy without leaving the ultra-high vacuum system. This allows to investigate the chemical structure and also the work function of the material: Especially the latter parameter, being a surface property and sensitive to adsorption/contamination, is likely to change upon vacuum break.

Figure 2 shows $\mathrm{x}$-ray photoelectron spectra for the $\mathrm{W} 4 \mathrm{f}$ core level of $\mathrm{WO}_{x}$. The spectrum shown in Figure $2 \mathrm{a}$ was measured on an as deposited sample with an as calculated stoichiometry of $\mathrm{WO}_{2.89}$. In contrast, the sample in Figure $2 \mathrm{~b}$ was treated with an oxygen plasma leading to its stoichiometry of $\mathrm{WO}_{2.97}$ and a negligible concentration of $\mathrm{W}_{2} \mathrm{O}_{5}$. Additionally both spectra show a significant signal of $\mathrm{WO}_{3}$ shifted by the oxygen vacancy induced BHI. This implies, that the changes in stoichiometry measured by the ratio of $\mathrm{WO}_{3}$ to $\mathrm{W}_{2} \mathrm{O}_{5}$ does not dominate the oxygen vacancy 


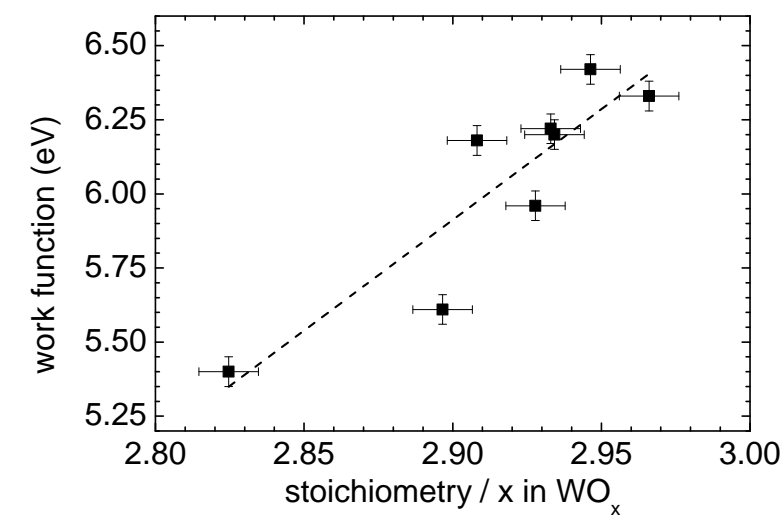

Figure 3: Work function of tungsten oxide plotted against the stoichiometry of the layer.

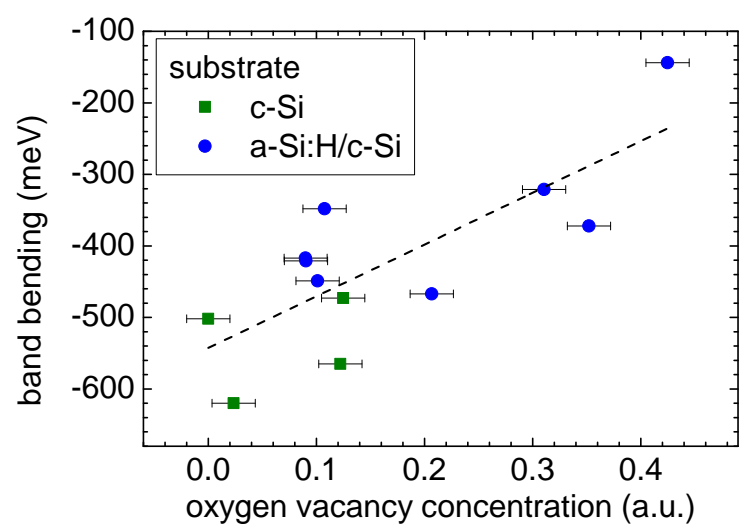

Figure 4: Band bending induced by tungsten oxide on n-type c-Si plotted against the oxygen vacancy concentration at the tungsten oxide surface.

density concentration. Most likely the measured oxygen vacancy signal is related to a defect density, which is small compared to the overall amount of oxygen in the layer, but has a strong electronic impact.

As explained in the discussion of figure 1 a high work function is favorable for a hole contact layer. The stoichiometry of tungsten oxide is known to influence its work function [22]. Combining measurements of the stoichiometry and He-UPS measurements of the work function of $\mathrm{WO}_{x}$ leads to the results depicted in Figure 3. A strong positive correlation of the work function and the stoichiometry of tungsten oxide is visible. An increase of the stoichiometry from 2.82 to 2.95 leads to an increase of the work function by roughly $1 \mathrm{eV}$ and $\mathrm{WO}_{x}$ with a stoichiometry close to $\mathrm{WO}_{3}$ has a work function of more than $6 \mathrm{eV}$. It is therefore suitable for application as hole contact layer in SHJ solar cells, or for application in the tunnel recombination contact with a (p)a-Si:H hole contact.

Apart from a suitable band alignment a strong band bending in the junction is needed to facilitate efficient charge separation in a solar cell. The band bending induced by $\mathrm{WO}_{x}$ on $\mathrm{n}$-type c-Si was measured using surface photovoltage and correlated to the chemical analysis presented earlier. The band bending induced by tungsten oxide on c-Si and 
(i)a-Si:H/c-Si samples is plotted in Figure 4 vs. the intensity fraction of the oxygen vacancy related signal in the W4f measurements. This intensity fraction is a qualitative measure for the density of oxygen vacancies in $\mathrm{WO}_{x}[23]$. We confirmed this assessment by measuring the BHI signal before and after annealing in air and vacuum $\left(200^{\circ} \mathrm{C}, 5 \mathrm{~min}\right)$ and found that the BHI intensity increases after annealing in vacuum, but vanishes after annealing in air.

These oxygen vacancies are known to constitute donor states [28] and the positive charge constituted by the activated donors lead to reduced band bending in the junction [29], or even Fermi-level pinning in the c-Si. Additionally, as can be seen in Figure 4, these oxygen vacancies are predominantly generated if the $\mathrm{WO}_{x}$ is deposited onto a-Si:H. A possible explanation would be hydrogen diffusion from the a-Si:H into the $\mathrm{WO}_{x}$ layer, as hydrogen can be used to reduce tungsten oxide to tungsten [30].

Overall, these results demonstrate that $\mathrm{WO}_{x}$ with a stoichiometry close to $\mathrm{WO}_{3}$ is suitable as a hole contact layer on silicon absorber layers, but the achievable band bending is limited by oxygen vacancies in the thermally evaporated material. This could explain the low fill factors reported for solar cells with tungsten oxide hole contacts on silicon absorbers $[8,9]$. Solar cell results obtained with the $\mathrm{WO}_{x}$ layers investigated here will be discussed in the following.

\subsection{Solar cell results}

Solar cells using tungsten oxide layers were fabricated and the overall band bending in these solar cells was measured using surface photovoltage. The tungsten oxide layers used for this experiment were deposited using varying deposition rates from 0.3 to $2 \mathrm{~nm} / \mathrm{min}$, had final thicknesses from 5 to $30 \mathrm{~nm}$ and featured varying microscopic properties. These microscopic properties and their influence on the band bending in these samples will be discussed in the following. The total thickness of $\mathrm{WO}_{x}$ and ITO was always adjusted to $80 \mathrm{~nm}$.

A first group of samples includes solar cells were the $\mathrm{WO}_{x}$ was deposited onto intrinsic amorphous silicon and therefore $\mathrm{WO}_{x}$ acts as the hole collection layer. A second group of samples includes a p-type amorphous silicon hole collector and $\mathrm{WO}_{x}$ layer. In this case the p-type amorphous silicon induces the band bending into the junction and the $\mathrm{WO}_{x}$ acts as interlayer at the (p)a-Si:H/ITO interface. The third group of samples includes our standard ITO/(p)a$\mathrm{Si}: \mathrm{H}$ hole contact and no $\mathrm{WO}_{x}$. Typical $\mathrm{j}(\mathrm{V})$ curves for all three sample types are shown in Figure 5. The short circuit current of these solar cells is limited, because of the planar wafer substrate and the variation between the solar cells is mainly due to variation of the ITO/ $\mathrm{WO}_{x}$ stack thickness and the resulting variation in front surface reflection.

The solar cell with a regular ITO/(p)a-Si:H contact shows a high fill factor of $76.7 \%$ and a $\mathrm{V}_{O C}$ of $708 \mathrm{mV}$. Adding a tungsten oxide interlayer at the ITO/(p)a-Si:H junction leads to a decrase in fill factor to about $69.2 \%$. The reason for this is the series resistance introduced by the low conductivity of the tungsten oxide, as can be deduced from the $\mathrm{j}(\mathrm{V})$ curve. The open circuit voltage stays comparable to the reference solar cell. Omitting the p-doped amorphous silicon leads to a further reduction of the fill factor and the introduction of an s-shape, as well as a decrease in open circuit voltage. This cannot be explained by an increase in series resistance and points towards weak carrier selectivity at the $\mathrm{p} / \mathrm{n}$-junction, or a hole transport barrier [31].

The band bending in solar cells of all three types with varying fill factors and open circuit voltages was measured to 


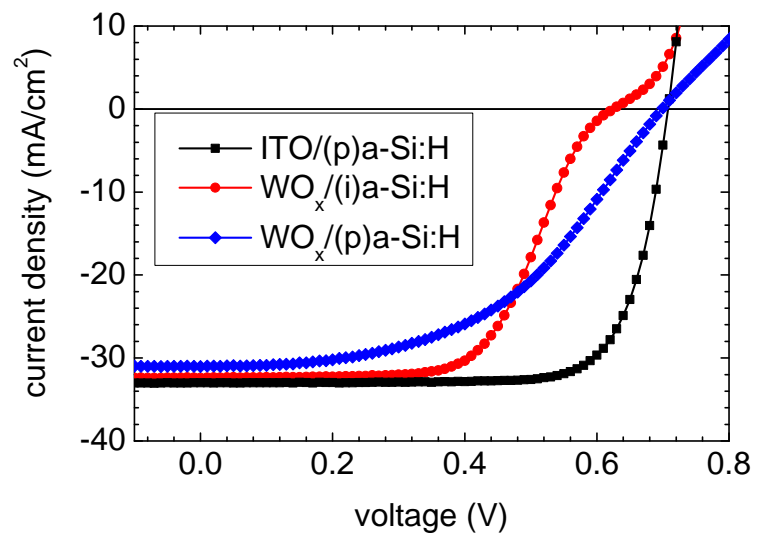

Figure 5: Solar cell $\mathrm{j}(\mathrm{V})$ curves of three different solar cells processed planar wafer, which are passivated by amorphous silicon. The three different solar cells are a regular silicon heterojunction solar cell with ITO as transparent conductive oxide and a p-doped amorphous silicon hole contact, a solar cell with a tungsten oxide interlayer between the ITO and the (p)a-Si:H and a solar cell without (p)a-Si:H and only tungsten oxide as hole contact layer.

further elucidate the reason for the poor charge selectivity at the tungsten oxide/silicon junction. Plots of the solar cells $\mathrm{V}_{\mathrm{OC}}$ and $\mathrm{FF}$ in dependence of the band bending are shown in Figure 6. Figure 6a shows the $\mathrm{V}_{\mathrm{OC}}$ of the solar cells against the band bending measured in the devices and Figure $6 \mathrm{~b}$ shows the FF values of the same solar cells plotted against the band bending. Over all three sample groups it is obvious that a high band bending leads to a high $\mathrm{V}_{\mathrm{OC}}$ and FF, whereas a low band bending leads to low $\mathrm{V}_{\mathrm{OC}}$ and FF values. The reason for the poor junction selectivity of the tungsten oxide/silicon junction seems to be a low band bending in this junction. Additionally the wide spreading of data points suggests that further factors are impacting the device output parameters. Comparing the regular ITO/(p)a$\mathrm{Si}: \mathrm{H}$ junctions with the $\mathrm{WO}_{x} /(\mathrm{p}) \mathrm{a}-\mathrm{Si}: \mathrm{H}$ junctions it is obvious that these junctions feature similar band bending but the solar cells including tungsten oxide display lower fill factors of about 65 to $70 \%$, while the open circuit voltages remain comparable. The decrease in fill factor can be explained by an increase in series resistance due to the low conductivity of the tungsten oxide layers, as can be deduced from the $\mathrm{j}(\mathrm{V})$ curves in Figure 5. The $\mathrm{V}_{\mathrm{OC}}$ of both cell types is comparable because the band bending is determined by the p-doping in the amorphous silicon hole contact layer. Both device types could reach comparable fill factors and efficiencies, if the conductivity, or thickness of the tungsten oxide is further optimized.

The third group of samples omits the p-doped amorphous silicon hole contact layer and employs a tungsten oxide/silicon junction. These devices display a wide range of band bendings and a wide spread of open circuit voltage and fill factor values. The scatter in the fill factor data is stronger and most likely due to variations in the tungsten oxide thickness and series resistance. Still overall open circuit voltage and fill factor are correlated to the band bending across the device. As established in Figure 4 this variation in band bending is based on a variation in oxygen vacancy density in this layers. The band bendings range from 350 to $575 \mathrm{meV}$ and the highest values are thus only $50 \mathrm{meV}$ below the band bending achieved in our standard ITO/(p)a-Si:H-structures. These layers supposedly have low oxygen 

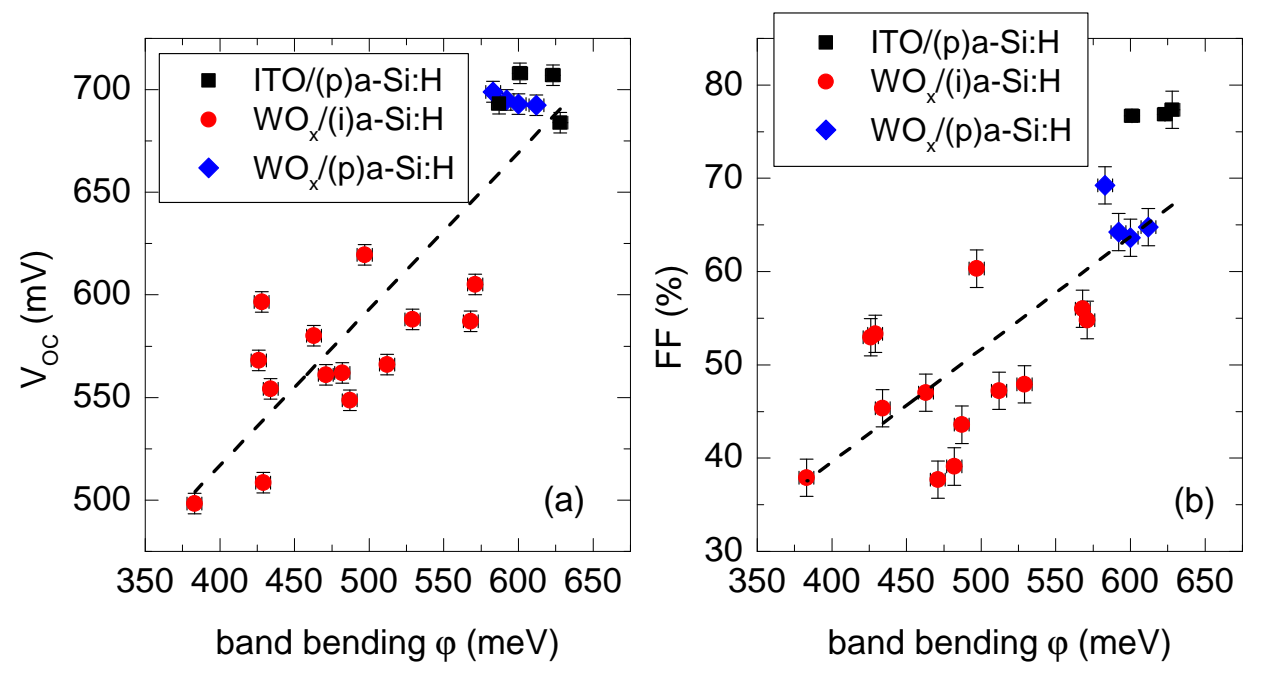

Figure 6: (a) VOC of SHJ solar cells with tungsten oxide contact layer plotted against the band bending measured in the same devices. (b) Fill factor of silicon heterojunction solar cells with tungsten oxide contact layers plotted against the band bending measured in the same devices.

vacancy densities and an optimization of the tungsten oxide conductivity and oxygen vacancy density could lead to optimized device properties. Note that the measured difference in band bending between the best tungsten oxide hole collectors and the p-doped amorphous silicon hole collectors is only about $50 \mathrm{meV}$, while the difference in open circuit voltage is about $100 \mathrm{mV}$. This in mainly due to the qualitative nature of band bending measurements based on surface photovoltage, which lose accuracy for high band bendings due to higher dember voltages [26].

Overall it is therefore understandable that extended oxygen vacancy generation in $\mathrm{WO}_{x}$ has to be prevented, to enable high band bendings across the tungsten oxide/silicon junction. Additionally oxygen vacancies are known donors in tungsten oxide [28]. Therefore a precise optimization of the oxygen vacancy density in tungsten oxide and the tungsten oxide stoichiometry is necessary to balance the requirements of high work function, high band bending across the junction and sufficient conductivity. Additionally sophisticated analysis of this oxygen vacancy density e.g. by capacitance voltage measurements [29] could proof worthwhile.

However the strong scatter in our data shows how difficult it is to achieve a good control of oxygen vacancies in $\mathrm{WO}_{x}$ during thermal evaporation. Therefore different methods for it's deposition like reactive sputtering [32] and chemical vapor deposition [33] should be employed.

\section{Conclusions}

$\mathrm{WO}_{x}$ deposited by thermal evaporation has been investigated as hole collection layer on crystalline silicon absorbers passivated by intrinsic amorphous silicon. Overall it was shown that $\mathrm{WO}_{x}$ is suitable as hole collection layer on silicon. If the stoichiometry is close to $\mathrm{WO}_{3}$ the work function is close to $6 \mathrm{eV}$ and thus high enough. Additionally, with $\mathrm{WO}_{x}$ on silicon it is possible to achieve comparable band bendings as with p-type amorphous silicon hole contact 
layers. The main drawback of $\mathrm{WO}_{x}$ is, that this band bending is reduced by deposition of $\mathrm{WO}_{x}$ on amorphous silicon. The most likely reason is the reduction of $\mathrm{WO}_{x}$ by hydrogen present in the amorphous silicon.

Additionally, $\mathrm{WO}_{x}$ prepared by thermal evaporation features a significant density of oxygen vacancy defects. These defects are known to be n-type dopants and constitute positive fixed charges. An increasing concentration of oxygen vacancies therefore leads to a decreasing band bending in the $\mathrm{WO}_{x} /$ silicon junction. A possible explanation is a shift in the Fermi-level in $\mathrm{WO}_{x}$ by the electron donating nature of the oxygen vacancy defects. These oxygen vacancy defects limit the $\mathrm{V}_{\mathrm{OC}}$ and fill factor of silicon solar cells with $\mathrm{WO}_{x}$ hole contacts, by decreasing the charge carrier selectivity of the junction.

Combining this results, it becomes clear that silicon based solar cells with tungsten oxide hole collectors can be limited by oxygen vacancy defects in $\mathrm{WO}_{x}$ and that a low concentration of oxygen vacancies in $\mathrm{WO}_{x}$ is necessary for a high band bending in the tungsten oxide silicon junction. Additionally the oxygen vacancy density has to be optimized in respect to the work function and conductivity of tungsten oxide. Therefore the exact density of oxygen vacancies in tungsten oxide has to be controlled for successful implementation of $\mathrm{WO}_{x}$ hole collection layers in silicon based solar cells. The results discussed in this article show that thermal evaporation is ill suited for this task and deposition methods allowing for the control of the oxygen fraction in $\mathrm{WO}_{x}$ should be employed. Among others, reactive sputtering and chemical vapor deposition $\mathrm{WO}_{x}$ are already discussed in the literature as promising alternatives.

\section{Acknowledgments}

The authors would like to thank Thomas Lußky, Erhard Conrad, Kerstin Jacob and Mona Wittig for wafer cleaning and vacuum system maintenance. Financial support was provided by the European Commission through the FP7ENERGY Project HERCULES (Grant No. 608498).

\section{References}

[1] K. Masuko, M. Shigematsu, T. Hashiguchi, D. Fujishima, M. Kai, N. Yoshimura, T. Yamaguchi, Y. Ichihashi, T. Mishima, N. Matsubara, T. Yamanishi, T. Takahama, M. Taguchi, E. Maruyama, S. Okamoto, Achievement of more than $25 \%$ conversion efficiency with crystalline silicon heterojunction solar cell, IEEE J. Photovolt. 4 (6) (2014) 1433-1435. doi:10.1109/JPHOTOV.2014.2352151.

[2] M. Taguchi, A. Yano, S. Tohoda, K. Matsuyama, Y. Nakamura, T. Nishiwaki, K. Fujita, E. Maruyama, 24.7\% record efficiency hit solar cell on thin silicon wafer, IEEE J. Photovolt. 4 (2014) 96-99. doi:10.1109/JPHOTOV.2013.2282737.

[3] A. Kanevce, W. K. Metzger, The role of amorphous silicon and tunneling in heterojunction with intrinsic thin layer (HIT) solar cells, J. Appl. Phys. 105 (2009) 094507

[4] K.-U. Ritzau, M. Bivour, S. Schröer, H. Steinkemper, P. Reinecke, F. Wagner, M. Hermle, TCO work function related transport losses at the a-Si:H/TCO-contact in SHJ solar cells, Sol. En. Mat. Sol. Cells 131 (2014) 9 - 13. doi:http://dx.doi.org/10.1016/j.solmat.2014.06.026.

[5] R. Rößler, C. Leendertz, L. Korte, N. Mingirulli, B. Rech, Impact of the transparent conductive oxide work function on injection-dependent a-Si:H/c-Si band bending and solar cell parameters, J. Appl. Phys. 113 (2013) 144513. doi:10.1063/1.4799042.

[6] B. Macco, D. Deligiannis, S. Smit, R. A. C. M. M. van Swaaij, M. Zeman, W. M. M. Kessels, Influence of transparent conductive oxides on passivation of a-Si:H/c-Si heterojunctions as studied by atomic layer deposited Al-doped ZnO, Semicond. Sci. Technol. 29 (12) (2014) 122001. 
[7] C. Battaglia, X. Yin, M. Zheng, I. D. Sharp, T. Chen, S. McDonnell, A. Azcatl, C. Carraro, B. Ma, R. Maboudian, R. M. Wallace, A. Javey, Hole selective $\operatorname{moo}_{x}$ contact for silicon solar cells, Nano Lett. 14 (2014) 967-971. doi:10.1021/n1404389u.

[8] M. Bivour, J. Temmler, H. Steinkemper, M. Hermle, Molybdenum and tungsten oxide: High work function wide band gap contact materials for hole selective contacts of silicon solar cells, Sol. En. Mat. Sol. Cells 142 (2015) 34 - 41. doi:http://dx.doi.org/10.1016/j.solmat.2015.05.031.

[9] L. G. Gerling, S. Mahato, A. Morales-Vilches, G. Masmitja, P. Ortega, C. Voz, R. Alcubilla, J. Puigdollers, Transition metal oxides as hole-selective contacts in silicon heterojunctions solar cells, Sol. En. Mat. Sol. Cells 145 (2016) 109 - 115. doi:http://dx.doi.org/10.1016/j.solmat.2015.08.028.

[10] C. Battaglia, S. M. de Nicolas, S. De Wolf, X. Yin, M. Zheng, C. Ballif, A. Javey, Silicon heterojunction solar cell with passivated hole selective $\mathrm{MoO}_{x}$ contact, Appl. Phys. Lett. 104 (2014) 113902. doi:http://dx.doi.org/10.1063/1.4868880.

[11] J. Geissbühler, J. Werner, S. Martin de Nicolas, L. Barraud, A. Hessler-Wyser, M. Despeisse, S. Nicolay, A. Tomasi, B. Niesen, S. De Wolf, C. Ballif, 22.5\% efficient silicon heterojunction solar cell with molybdenum oxide hole collector, Appl. Phys. Lett. 107 (2015) 081601. doi:http://dx.doi.org/10.1063/1.4928747.

[12] X. Yang, P. Zheng, Q. Bi, K. Weber, Silicon heterojunction solar cells with electron selective $\mathrm{TiO}_{x}$ contact, Sol. En. Mat. Sol. Cells 150 (2016) 32 - 38. doi:http://dx.doi.org/10.1016/j.solmat.2016.01.020.

[13] Y. Zhang, W. Cui, Y. Zhu, F. Zu, L. Liao, S.-T. Lee, B. Sun, High efficiency hybrid PEDOT:PSS/nanostructured silicon Schottky junction solar cells by doping-free rear contact, Energy Environ. Sci. 8 (2015) 297-302. doi:10.1039/C4EE02282C.

[14] J. Bullock, M. Hettick, J. Geissbühler, A. J. Ong, T. Allen, C. M. Sutter-Fella, T. Chen, H. Ota, E. W. Schaler, S. D. Wolf, C. Ballif, A. Cuevas, A. Javey, Efficient silicon solar cells with dopant-free asymmetric heterocontacts, Nature Energy 2 (2016) 15031.

[15] J. Meyer, S. Hamwi, M. Krger, W. Kowalsky, T. Riedl, A. Kahn, Transition metal oxides for organic electronics: Energetics, device physics and applications, Adv. Mater. 24 (40) (2012) 5408-5427. doi:10.1002/adma.201201630.

[16] M. T. Greiner, M. G. Helander, W.-M. Tang, Z.-B. Wang, J. Qiu, Z.-H. Lu, Universal energy-level alignment of molecules on metal oxides, Nat. Mater. 11 (2012) 76-81. doi:10.1038/nmat3159.

[17] B. Macco, M. F. J. Vos, N. F. W. Thissen, A. A. Bol, W. M. M. Kessels, Low-temperature atomic layer deposition of $\mathrm{MoO}_{x}$ for silicon heterojunction solar cells, Phys. Status Solidi RRL. 9 (2015) 393-396. doi:10.1002/pssr.201510117.

[18] J. Ziegler, M. Mews, K. Kaufmann, T. Schneider, A. Sprafke, L. Korte, R. Wehrspohn, Plasma-enhanced atomic-layer-deposited MoO $_{x}$ emitters for silicon heterojunction solar cells, Appl. Phys. A 120 (2015) 811-816. doi:10.1007/s00339-015-9280-3.

[19] M. Mews, T. F. Schulze, N. Mingirulli, L. Korte, Hydrogen plasma treatments for passivation of amorphous-crystalline silicon-heterojunctions on surfaces promoting epitaxy, Appl. Phys. Lett. 102 (2013) 122106. doi:10.1063/1.4798292.

[20] M. Mews, C. Leendertz, M. Algasinger, S. Koynov, L. Korte, Amorphous/crystalline silicon heterojunction solar cells with black silicon texture, Phys. Status Solidi RRL. 8 (10) (2014) 831-835. doi:10.1002/pssr.201409327.

[21] F. Bussolotti, L. Lozzi, M. Passacantando, S. L. Rosa, S. Santucci, L. Ottaviano, Surface electronic properties of polycrystalline $\mathrm{WO}_{3}$ thin films: a study by core level and valence band photoemission, Surf. Sci. 538 (1ф2) (2003) 113 - 123. doi:http://dx.doi.org/10.1016/S00396028(03)00696-4.

[22] J.-S. Lee, I.-H. Jang, N.-G. Park, Effects of oxidation state and crystallinity of tungsten oxide interlayer on photovoltaic property in bulk hetero-junction solar cell, J. Phys. Chem. C 116 (2012) 13480-13487. doi:10.1021/jp2122505.

[23] M. J. Son, S. Kim, S. Kwon, J. W. Kim, Interface electronic structures of organic light-emitting diodes with $\mathrm{WO}_{3}$ interlayer: A study by photoelectron spectroscopy, Org. Electron. 10 (2009) 637 - 642. doi:http://dx.doi.org/10.1016/j.orgel.2009.02.017.

[24] R. Cimino, A. Giarante, K. Horn, M. Pedio, Line broadening in semiconductor core level photoemission induced by barrier height inhomogeneity, Surf. Sci. 331 (1995) 534 - 539. doi:http://dx.doi.org/10.1016/0039-6028(95)00300-2.

[25] M. Vasilopoulou, L. C. Palilis, D. G. Georgiadou, A. M. Douvas, P. Argitis, S. Kennou, L. Sygellou, G. Papadimitropoulos, I. Kostis, N. A. Stathopoulos, D. Davazoglou, Reduction of tungsten oxide: A path towards dual functionality utilization for efficient anode and cathode interfacial layers in organic light-emitting diodes, Adv. Funct. Mater. 21 (2011) 1489-1497. doi:10.1002/adfm.201002171. 
[26] K. Heilig, Determination of surface properties by means of large signal photovoltage pulses and the influence of trapping, Surf. Sci. 44 (1974) 421-37.

[27] R. Varache, C. Leendertz, M. Gueunier-Farret, J. Haschke, D. Munoz, L. Korte, Investigation of selective junctions using a newly developed tunnel current model for solar cell applications, Sol. En. Mat. Sol. Cells 141 (2015) 14 - 23. doi:http://dx.doi.org/10.1016/j.solmat.2015.05.014

[28] M. T. Greiner, L. Chai, M. G. Helander, W.-M. Tang, Z.-H. Lu, Transition metal oxide work functions: The influence of cation oxidation state and oxygen vacancies, Adv. Funct. Mater. 22 (21) (2012) 4557-4568. doi:10.1002/adfm.201200615.

URL http://dx.doi.org/10.1002/adfm. 201200615

[29] B. Shin, J. R. Weber, R. D. Long, P. K. Hurley, C. G. Van de Walle, P. C. McIntyre, Origin and passivation of fixed charge in atomic layer deposited aluminum oxide gate insulators on chemically treated ingaas substrates, Appl. Phys. Lett. 96 (15) (2010) 152908.

[30] J. O. Hougen, R. R. Reeves, G. G. Mannella, Reduction of tungsten oxides with hydrogen, Ind. Eng. Chem. 48 (2) (1956) 318-320. doi:10.1021/ie50554a042.

[31] M. Mews, M. Liebhaber, B. Rech, L. Korte, Valence band alignment and hole transport in amorphous/crystalline silicon heterojunction solar cells, Appl. Phys. Lett. 107 (2015) 013902. doi:http://dx.doi.org/10.1063/1.4926402.

[32] A. Akl, H. Kamal, K. Abdel-Hady, Characterization of tungsten oxide films of different crystallinity prepared by RF sputtering, Physica B: Condensed Matter 325 (2003) 65 - 75. doi:http://dx.doi.org/10.1016/S0921-4526(02)01431-X.

[33] Z. S. Houweling, J. W. Geus, M. de Jong, P.-P. R. Harks, K. H. van der Werf, R. E. Schropp, Growth process conditions of tungsten oxide thin films using hot-wire chemical vapor deposition, Mater. Chem. Phys. 131 (2011) 375 - 386. doi:http://dx.doi.org/10.1016/j.matchemphys.2011.09.059. 